\title{
Knowledge and practices relating to malaria in a semi-urban area of Cameroon: choices and sources of antimalarials, self-treatment and resistance
}

\author{
Dickson Shey Nsagha ${ }^{1,2,8}$, Anna Longdoh Njunda ${ }^{3}$, Henri Lucien Foumou Kamga ${ }^{3}$, Sarah Mboshi Nsagha ${ }^{4}$, Jules Clement Nguedia \\ Assob $^{5}$, Charles Shey Wiysonge ${ }^{6}$, Earnest Njih Tabah ${ }^{7}$, Alfred Kongnyu Njamnshi ${ }^{8}$
}

${ }^{1}$ Department of Public Health and Hygiene, Medicine Programme, Faculty of Health Sciences, University of Buea, Buea, Cameroon, ${ }^{2}$ Department of Epidemiology, Medical Statistics and Environmental Health (Formerly Department of Preventive and Social Medicine), Faculty of Public Health, College of Medicine, University of Ibadan, Ibadan, Nigeria, ${ }^{3}$ Department of Medical Laboratory Sciences, Faculty of Health Sciences, University of Buea, Buea, Cameroon, ${ }^{4}$ Department of Educational Psychology, Faculty of Education, University of Buea, Buea, Cameroon, ${ }^{5}$ Department of Biomedical Sciences, Faculty of Health Sciences, University of Buea, Buea, Cameroon, ${ }^{6}$ School of Child and Adolescent Health, University of Cape Town, Cape Town, South Africa, ${ }^{7}$ National Programme for Leprosy, Buruli Ulcer \& Yaws Control, Ministry of Public Health, Yaoundé, Cameroon, ${ }^{8}$ Department of Internal Medicine \& Specialties (Dermatology and Neurology), Faculty of Medicine \& Biomedical Sciences, University of Yaoundé I, Yaoundé, Cameroon

${ }^{8}$ Corresponding author: DS Nsagha, Department of Public Health and Hygiene, Medicine Programme, Faculty of Health Sciences, University of Buea, P.O. Box 63, Buea, Cameroon

Key words: Malaria, knowledge, practices, antimalarials, choices, sources, self-medication, resistance, Cameroon

Received: 19/01/2011 - Accepted: 09/05/2011 - Published: 25/05/2011

\begin{abstract}
Introduction: Malaria is a major public health problem in Sub-Saharan Africa where it kills a child under the age of five every 30 seconds. In Cameroon, malaria accounts for $40-45 \%$ of medical consultations, $57 \%$ of hospitalization days and $40 \%$ of mortality among children below 5 years. Community knowledge and practices can enhance the fight against this disease. The aim of the study was to make a local analysis of the people's knowledge and practices relating to the choice and source of antimalarials, self-medication, malaria dosage and resistance in order to establish behavioural baseline and epidemiological determinants and their implications for malaria control. Methods: The design was a community-based cross-sectional study in a semi-urban setting. The survey consisted of 253 volunteer participants (from among 350 contacted) from different socio-demographic backgrounds to whom structured questionnaires were administered. The respondent's consent was sought and gained and subjects who could not read or write or understand English language were communicated to in the local language. The questionnaire was administered by trained interviewers according to the schedule of the respondent. The data was analysed using SPSS. Results: Antimalarials commonly cited for malaria treatment were chloroquine $(26.1 \%)$ and nivaquine $(14.6 \%)$ and analgesics: panadol $(23 \%)$ and paracetamol $(12.3 \%)$ including native drugs $(6.3 \%)$. $141(55.7 \%)(95 \%$ confidence interval (CI): 49.6-61.8\%) participants practiced self-medication of malaria. $26.1 \%$ participants knew the correct adult malarial dosage for chloroquine or nivaquine. $125(40.4 \%)(95 \%$ CI: $34.4-46.7 \%)$ participants got their antimalarials from health centers, $27(10.6 \%)$ from shops, $24(9.5 \%)$ from hawkers, $23(9.1 \%)$ from the open market and $16(6.3 \%)$ from herbalists. $66(26.1 \%)(95 \%$ CI: 20.7-31.5\%) participants knew the correct adult dosage for chloroquine or nivaquine treatment of malaria. $85(33.6 \%)(95 \%$ CI: $27.8-36.6 \%)$ participants had correct knowledge of malarial resistance. Of the $85(33.6 \%)$ participants who had correct knowledge of antimalarial drug resistance, $52(20.6 \%)$ ascribed antimalarial drug resistance to continuous fever for a long time during treatment, 15 (5.9\%) to serious fever during treatment and $18(7.1 \%)$ when chloroquine does not stop fever. 23(27.1\%) participants with correct knowledge of malarial resistance were in the 31-35 age group bracket compared with other age groups $(P=0.1)$. There was a significant difference in correct knowledge of malarial resistance and participant's profession ( $(=0.0)$. Conclusion: Malaria self-medication is common in Ndu but knowledge of antimalarial drug resistance is poor. Improvement in the self-treatment of malaria could be attained by providing clear information on choices of drugs for malaria treatment. Proper health information on the rational use of ant-malarial drugs must be provided in an appropriate manner to all groups of people in the society including village health workers, women associations, churches, school children, "Mngwah" opinion leaders, herbalists, health workers and chemists. Self-medication should be improved upon by giving correct information on the dosage of malaria treatment on radio, television, posters and newspapers because banning it will push many people to use it in hiding.
\end{abstract}

\section{Pan African Medical Journal. 2011; 9:8}

This article is available online at: http://www.panafrican-med-journal.com/content/article/9/8/full/

(c) Dickson Shey Nsagha et al. The Pan African Medical Journal - ISSN 1937-8688. This is an Open Access article distributed under the terms of the Creative Commons Attribution License (http://creativecommons.org/licenses/by/2.0), which permits unrestricted use, distribution, and reproduction in any medium, provided the original work is properly cited. 
Malaria is the major cause of morbidity and mortality in the tropics [1]. Antimalarial drug resistance, developing from two major factors: prescribing behaviour of health workers and self-treatment of the community is a hurdle to the control of this disease. In the 1990s, the WHO recommended that in areas or seasons of high malaria endemicity, malaria treatment should be given to all patients with fever or a history of fever [2]. The current malaria treatment guideline by WHO [3] stipulates that prompt parasitological confirmation by microscopy or alternatively by RDTs is recommended in all patients suspected of malaria before treatment is started; treatment solely on the basis of clinical suspicion should only be considered when a parasitological diagnosis is not possible. Cameroon adopted the current WHO guideline for malaria treatment and changed from chloroquine or amodiaquine monotherapy to artemisinin-based combination therapy (AS/AQ) in 2005 [4,5]. Although presumptive treatment of febrile illnesses with antimalarials is part of the national health policy in most African countries, it results in the unnecessary prescription of antimalarials [6]. These treatment policies are common in Cameroon where laboratories are sparsely equipped and where laboratory services are not readily available especially in the peripheral areas. In Cameroon, malaria accounts for $40-45 \%$ of medical consultations, $57 \%$ of hospitalization days and $40 \%$ of mortality among children below 5 years of age [7]. Proper health education of village mothers has been proven to reduce underfive malaria morbidity and mortality significantly in Cameroon [8]. In a study conducted among 1197 health service users in northern Cameroon, only $1 \%$ identified mosquitoes as a source of transmission [9]. Contrary to Cameroonians who have poor knowledge of malaria determinants [9], French nationals living in Cameroon are well informed of malaria [10]. Deficient knowledge on malaria treatment guidelines and the irrational use of antimalarials [4] has been reported in Cameroon. There is also evidence of major differences in malaria treatment, prophylaxis and diagnosis in Cameroon [11].

Inadequacy of resources and trained personnel in health care, necessitate the purchase of antimalarials over the counter in many African countries [12]. Self-medication as a means of malaria treatment is common in Cameroon [13]. Fifty six percent women declared that they had taken either chloroquine or amodiaquine during pregnancy because they thought they had malaria [13]. In another separate study in Cameroon [14], most $(56.8 \%)$ participants admitted that they used drugs for the prevention of malaria, most $(95 \%)$ of these using chloroquine. Preventing the foci of resistant falciparium malaria from widening requires the rational use of antimalarials [15].

The emergence of chloroquine resistance malaria was first documented in south-western Cameroon (an area hyperendemic for malaria) in 1985 [16]. In 1995 [13], a $10 \%$ antimalarial drug resistance to chloroquine was reported from Southern Cameroon. More than 50\% chloroquine resistance of Plasmodium falciparium was reported from the same area in 1997 [14]. Although such resistance has spread rapidly throughout the country, the amodiaquine-artesunate combination is the drug of choice for malaria treatment in Cameroon nowadays [7].

Tremendous efforts towards malaria control in Cameroon have not been cost effective [17-19] resulting in difficulties of eradication of the malaria vectors [20]. Control strategies require public support and the extent of people's cooperation can determine the success or failure of the entire campaign against malaria [21]. This support entails an assessment of the people's knowledge and practices relating to the choice and sources of antimalarials, self-treatment, dosage and resistance, hence this study was conducted.

\section{Methods}

\section{Study Area}

$\mathrm{Ndu}$ is a small semi-urban community with a population of slightly over twenty thousand inhabitants located at latitude $6^{\circ} 24^{\prime} 0 \mathrm{~N}$, longitude $10^{\circ}$ $46^{\prime} \mathrm{OE}$, and at an altitude of 1827 meters above sea level [22] in the North West Region of Cameroon. It is the highest point in Donga-Mantung division and is always very cold. Ndu is the headquarters of Ndu subdivision in the Wimbum tribe. The Wimbum tribe constitutes the main inhabitants and their dialect is called "Limbum". Other major tribes in Ndu include Nso, Hausa, Fulani, Yamba and Igbo (Nigerians). It is the central commercial point and acts as one of the main exit and entry routes to Nigeria. Ndu is situated about $160 \mathrm{~km}$ from the regional capital, Bamenda. Neighbouring villages of Wowo, Mbipgo, Njillah and Kakar where the tea plantation is located were also included in the study.

There is a District Hospital in Ndu and the Baptist Health Centre and the "Ndu Tea Estate" Health Centre. There are two main hospitals in Banso and one in Nkambe, each about an hour's drive from Ndu. Patent medicine stores are common in this locality and antimalarials are dispensed on daily basis and weekly market days by untrained hawkers. There is no trained pharmacist in Ndu. Traditional medical care is very common in Ndu and its environs and disease causation, prevention and treatment are always linked to superstition. The "nwe chep" or traditional medicine man is common in this locality.

Ndu is mainly a farming area and most inhabitants are farmers. There are a lot of artificial forests. The climate is made up of two distinct seasonsa long rainy season from March to September and a short dry season from October to February. Temperatures can vary from $17^{\circ} \mathrm{C}$ in the rainy season around August and during harmattan to about $25^{\circ} \mathrm{C}$ in the dry season around January. Malaria transmission is seasonal and occurs, mostly, from May to September. Malaria is the main mosquito-borne disease in the locality and as such a public health problem of primary importance. Other diseases common in Ndu are HIV/AIDS, tuberculosis, intestinal helminthes, gastro-enteritis, cough, typhoid, herpes zoster, and skin infections. Cases of filariasis are common but no other mosquito-borne diseases such as yellow fever and elephantiasis have been reported from Ndu to the best of our knowledge. Ndu is predominantly a Christian community. The study took place from July to August 2002.

Ethical approval was obtained from the North West Provincial (now Regional) Delegation of Public Health in Bamenda. 


\section{Study Sample, data collection and analysis}

We used a convenient sample of 253 participants. The survey consisted of 112 men and 141 women with different professions (teaching, unskilled labourers, housewives, students, farmers, technicians, nurses, midwives, tea harvesters and cleaners) and age groups. The respondent's consent was sought and gained by explaining the aims of the study. Subjects who could not read or write or understand pidgin English and English were communicated to in "Limbum", the local language of the Wimbum tribe. A questionnaire was administered to volunteers by trained interviewers according to the time schedule of the participants. Those who could read and/or write answered the questions immediately or at their convenience. The interviewers later collected the filled questionnaires. For those who could not read or write, the interviewers had to meet them at agreed times at home or specific locations to interpret the questionnaire and the participant's responses were recorded. In institutions such as schools, farmer's cooperative societies, group workers like the tea plantation, weekly and monthly contribution meetings known here as "Mngwah", permission was sought from the leaders after introducing the study and volunteers indicated consent by raising their hands and questionnaires were then administered. In each case, care was taken not to deviate from the closed structure questionnaire. The confidentiality of the information provided was ascertained to the participants. The questionnaire contained independent variables on age, sex, profession and place of abode and questions on antimalarials and dosage, their sources, malaria self-medication and resistance constituted the dependent variables. The chi-square test and confidence intervals were used to compute proportions.

\section{Results}

The demographic characteristics of the study sample are shown in Table 1. Knowledge about the drugs used for the treatment of malaria was very high with $152(60.1 \%)$ participants citing different antimalarial drugs and $106(41.9 \%)$ analgesics. The drugs used for the practice of self-treatment (by self-treatment or self-medication, we mean, participants procure and use antimalarials on their own without medical advice or buy them from the roadside drug vendors or quacks) by the participants are shown in Figure 1. 141(55.7\%) (95\% CI: 49.6-61.8\%) participants practiced selftreatment of malaria with medication from various sources while $112(44.3 \%)(95 \% \mathrm{CI}: 38-50.6 \%)$ did not practice it. More secondary than primary school participants $(82(58.2 \%)$ versus $59(41.8 \%)$ respectively) practiced self-treatment when they suspect malaria $(\mathrm{P}=0.0)$. The sources of anti-malarials as stated by participants are shown in Figure 2.

Only $66(26.1 \%)(95 \%$ CI: $20.7-31.5 \%)$ participants knew the correct adult dosage for chloroquine or nivaquine treatment of malaria while 187 (73.9\%) did not know. Knowledge of antimalarial drug resistance was poor with 85(33.6\%) (95\% CI: 27.8-36.6\%) participants having the correct knowledge and $168(66.4 \%)$ (95\% CI: 60.2-72.2\%) having incorrect knowledge. The reasons justifying antimalarial drug resistance as stated by the participants show that there was a statistically significant difference between knowledge of antimalarial drug resistance among the male and female participants as shown in Table $2(\mathrm{p}=0.01)$. 30(26.8\%) (95\%CI: 19.0-35.2\%) men and 55(39.0\%) (95\%CI: 31-47\%) women gave correct reasons for antimalarial drug resistance. Table 3 shows that knowledge of antimalarial drug resistance was highest among the age group 31-35. No statistically significant relationship was established between correct knowledge of antimalarial drug resistance with age group ( $p=0.1$ ). From Table 4, most participants who had correct knowledge of antimalarial drug resistance were the unemployed, teachers and labourers. A statistically significant relationship was established between knowledge of antimalarial drug resistance and the profession of the participants $(p=0.0)$.

\section{Discussion}

There is increasing recognition among health professionals that improving the health of poor people depends upon adequate understanding of the socio-cultural aspects of the context in which public health programmes are implemented [23]. Our study on knowledge and practices is important because it investigated the health seeking behaviour and provides information on health-seeking practices on malaria of the inhabitants of Ndu. The survey also enabled us to understand the culture-specific knowledge on malaria determinants and treatment practices and to relate them to the treatment policy in Cameroon.

\section{Drugs used for the treatment of malaria}

This study took place in 2002 when chloroquine was still the drug of choice for malaria treatment in Cameroon. The most common antimalarial used in Ndu for self-medication was chloroquine even though it has been banned in Cameroon since 2003 because of widespread resistance(in September 2008, the lead author observed hawkers selling chloroquine to patients in Ndop-about 120km from Ndu). In 2005, Cameroon changed the malaria treatment policy from chloroquine or amodiaquine monotherapy to artemisinin-based combination therapy (AS/AQ) [4,5]. As noted by Sayang and colleagues [4], chloroquine remained available in confessional health facilities in rural areas in Cameroon in 2005. Health education to explore beliefs and to correct misconceptions should precede and accompany the introduction of technological interventions in malaria control programmes in traditional Cameroon societies as noted by Einterz [9]. Drugs used for the treatment of malaria in the study area included antimalarials (chloroquine, nivaquine, fansidar, camoquine), analgesics (panadol, paracetamol, aspirine, cafenol) and native drugs or "Mchep à lah". Knowledge of the conventional drugs used for the treatment of malaria was very high. This could be due to the strategic location of the town on the border with Nigeria which allows interactions with drug sellers or quack drug dispensers from unauthorized sources. Self-medication has been confirmed in Western Kenya [24] and Dakar, Senegal [25]. This practice may be due to relaxed rules on drug acquisition and can be controlled through stricter rules on anti-malarial drugs procurement. However, self-medication cannot be fully condemned as lives are often saved through this practice. It could be improved upon by educating the local population on the correct use of drugs and their dosages.

\section{Sources of drugs used for the treatment of malaria}

More than $50 \%$ of participants got their antimalarials from unauthorized sources which can act as a hurdle to the control of the disease. In 2005 , Nkuo Akenji and associates [8] found that proper education of Cameroonian villagers on malaria and presence of health facilities are important 
strategies that could reduce malaria morbidity and mortality significantly. Most of the drugs used for treating malaria were from unauthorised sources. This agrees with the findings of a Zambian study [26] in isolated rural settings; that the most concerned by malaria prevalence, have difficulties to be educated about treatment progresses and have limited access to official information. Majority of the participants were characterized by low income workers but this did not affect the respondent's source(s) of antimalarials because these drugs are available from many sources including "chemist" shops or medicine stores owned by lay business people who are not trained or licensed pharmacists. In a similar study in Kenya [27] proportions of these responses were much higher. Many reasons could be given for these differences: beliefs that there is no respect of patients at health institutions, cost of acquiring antimalarials and waiting time before being attended to in a health facility [27,28]. Getting antimalarials from hawkers, unauthorized patent medicine stores, injections and other drugs from unauthorized sources in the "quarters", the open market and the "Nwe chep" are common in this locality. The practice of consulting the traditional doctor or "Nwe chep" for the causes and prevention of illnesses is common and may explain why some participants patronize traditional doctors. Our findings agree with the work of Good [29] who discovered that traditional ideas may be erroneous from the biomedical perspective and form obstacles to appropriate behaviour and treatment seeking practices.

The presence of many patent medicine stores and other drug sources in the locality could be a motivating factor for the population to get their antimalarials since no medical prescription is needed before drugs are sold. Self-medication can lead to antimalarial drug resistance because there is under- and over-dosing since most drug dispensers are not trained medical personnel. Also, most of the people did not know the correct chloroquine/nivaquine malaria dosage. Self-medication is not limited to this study area; it is common in other areas of Africa [24,25,30,31]. People self-medicate because of the convenience of the readily available drugs they store at home [32], they avoid long distances to the health care provider or lack funds to visit recognized health facilities.

\section{Variation of knowledge and practice with demographic characteristics of participants}

In Africa, malaria affects mainly young children and pregnant women [15,33] and women have the responsibility for providing nursing and health care for children [34]. Women are therefore more likely to seek and use antimalarials [30] than men, hence their better knowledge of antimalarial drug resistance. Knowledge of antimalarial drug resistance in the study area was low with only $33.6 \%$ participants having the correct knowledge. Since self-medication is common in this area, the respondent's knowledge of antimalarial drug resistance was expected to be high. This could be due to the respondents' experiences from prolonged treatment, severe fever or severe fever during treatment (reasons cited by participants for antimalarial drug resistance), and delays in finding the cause of the illness like consulting the "Nwe chep" or which "god" to appease; hence antimalarial drug resistance is never acknowledged as a problem. Our findings on antimalarial drug resistance agree with the work of Sayang and associates [4] who found persistent fever occurring at day 3 post-treatment (associated or not associated with other clinical signs) as the main criteria to evaluate malaria therapeutic failure in Cameroon.

In professions such as in medicine and teaching where people have attained a certain level of education, there was a statistically significant difference in the knowledge of anti malarial drug resistance between these categories and other professions that don't require any formal educational training. Older people (>31years) may have suffered from many episodes of malarial treatment and tend to know more of antimalarial drug resistance than the younger ones.

\section{Conclusion}

Home treatment or self-medication of malaria is very common and can easily lead to drug resistance in this locality. The best solution to selfmedication is that it should be improved upon. To ban it means encouraging people to practice it more in hiding. Improvement in self-treatment of malaria could be effected by providing clear information on choices of drugs for malaria treatment. Proper health information on the rational use of anti-malarial drugs must be provided in an appropriate manner to all groups of people in the society including village health workers, women associations, churches, school children, "Mngwah" opinion leaders, herbalists, health workers and chemists. Advertisements of the correct dosage of common antimalarials on radio, television, posters and newspapers would be good. Training of hawkers and drug store keepers of Ndu on antimalarial dosages and dispensing can also improve the control of the disease.

\section{Competing interests}

The authors declare they have no competing interests.

\section{Authors' contributions}

DSN conceived and designed the study, analysed the data, drafted the manuscript and substantially revised it, ALN, CUWS and AKN substantially revised the manuscript for academic content, SMN conceived the study and substantially revised the manuscript, JCNA, ENT and HLFK participated in the write-up and revision. All authors read and approved the manuscript.

\section{Acknowledgements}

Tantoh Alfred Arunah and George Mbunwe Nsagha assisted in data collection. No external funding was received for this work. 
Table 1: Demographic characteristics of the study participants $(n=253)$

Table 2: Variation of knowledge of reasons of antimalarial drug resistance with gender among the study participants $(n=253)$

Table 3: Variation of knowledge of antimalarial drug resistance among different age groups of the study participants $(n=253)$

Table 4: Variation of knowledge of antimalarial drug resistance and profession of the study participants $(n=253)$

Figure 1: Drugs used for the practice of self-treatment of malaria as stated by the study participants $(n=253)$

Figure 2: Sources of getting anti-malarials as stated by the study participants $(n=253)$

\section{References}

1. Manson-Bahr PCE, Bell DR . Malaria and babesiosis. In: Manson's Tropical Diseases, 19th ed. London, Bailliere Tindall, 1987; Pages 3-51

2. Schapira AA. A standard protocol for assessing the proportion of children presenting with febrile disease who suffer from malarial disease. WHO.1994; WHO/MAL/94/069. World Health Organisation, Geneva

3. WHO (2010). WHO releases new malaria guidelines for treatment and procurement of medicines. Available at:http://www.who.int/mediacentre/news/releases/2010/malaria_20100308/en/index.html. Accessed 8th March 2011

4. Sayang C, Gausseres M, Vernazza-Licht N, Malvy D, Bley D, Millet P. Treatment of malaria from monotherapy to artemisinin-based combination therapy by health professionals in rural health facilities in southern Cameroon. Malar J. 2009 Jul 29;8:174. This article on PubMed

5. Sayang C, Gausseres M, Vernazza-Licht N, Malvy D, Bley D, Millet P. Treatment of malaria from monotherapy to artemisinin-based combination therapy by health professionals in urban health facilities in Yaounde, Central Province, Cameroon. Malar J. 2009 Jul 29;8:176. This article on PubMed

6. Jonkman A, Chibwe RA, Khoromana CO, Liebunya UL, Chaponda ME, Kandiero GE, Molyneux ME , Taylor TE. Cost-saving through microscope based versus presumptive diagnosis of malaria in adult outpatients in Malawi. Bull World Health Organ. 1995;73(2):223-7. This article on PubMed

7. Ministère de la Santé Publique. Plan stratégie national de la lutte contre le paludisme au Cameroun 2007-2010. 2007; Pages 1-134

8. Nkuo Akenji TK, Ntonifor NN, Ching JK, Kimbi HK, Ndamukong KN, Anong DN, Boyo MG, Titanji VP. Evaluating a malaria intervention strategy using knowledge, practices and coverage surveys in rural Bolifamba, southwest Cameroon. Trans R Soc Trop Med Hyg. 2005;99(5):325-32. This article on PubMed

9. EinterzEM. Perceptions of malaria transmission, presentation and management in northern Cameroon. Trans R Soc Trop Med Hyg. 2003 Jan-Feb;97(1):51-2. This article on PubMed

10. De Quincenet G, Louis FJ,Gélas H. Paludisme: conduites, attitudes, pratiques et croyances des expatriés français à Yaoundé, Cameroun, en 1993 Bulletin Liais Document. OCEAC. 1994; 27(2) : 61-64

11. Ndumbe PM. Curative and preventive treatment of uncomplicated malaria in public health institutions in Cameroon. Eur J Epidemiol. 1989; 5(2):183-88. This article on PubMed

12. Lore W. Emerging and remerging global microbial threats. East Afr Med J. 1996; 73: 1-2. This article on PubMed

13. Cot M, Le Hesran JY, Miailhes P, Esveld M, Etya'ale D, Breart G. Increase of birth weight following chloroquine chemoprophylaxis during the first pregnancy : Results of a randomised trial in Cameroon. Am J Trop Med Hyg. 1995 Dec;53(6):581-5. This article on PubMed

14. Le Hesran YY, BoudinC, Cot M, Personne P, Chambon R, Foumane V, Verhave JP, De Vries C. In-vivo resistance of Plasmodium falciparium to chloroquine and amodiaquine in South Cameroon and age-related efficacy of the drugs. Ann Trop Med Parasitol. 1997 Sep;91(6):661-4. This article on PubMed

15. WHO. Practical chemotherapy of malaria. Report of a WHO Scientific Group. Technical report series No

16. Brasseur P, Kouamova J, Mayou-Somo R, Druilhe P. Multi-drug resistant falciparium malaria in Cameroon in 1987-1988 II Mafloquine resistance confirmed in vivo and in vitro and its correlation with quinine resistance. Am J Trop Med Hyg. 1992 Jan;46(1):8-14. This article on PubMed 
17. Desfontaine M, Gelas H, Gabon J, Goghomu A, Kouka-Bemba D, Camavale P. Evaluation des pratiques et des couts de lutte anti vectorielle a l'échelons familial en Afrique centrale II Ville de Douala (Cameroun), juillet 1988. Ann Soc Belg Med Trop. 1990 Jun;70(2):137-44. This article on PubMed

18. Fondjo E, Robert V, Le Goff G, Toto JC, Carnevale P. Le paludisme urbain a Yaoundé(Cameroun) II Etude entomologique dans deux quartiers peu urbanises. Bull Soc Pathol Exot. 1992;85(1):57-63. This article on PubMed

19. Louis JP, Trebucq A, Gelas H,Fondjo E, Manga L,Toto JC, Carnevale P. Le paludisme-maladie dans la ville de Yaoundé (Cameroun) Prise en charge et lutte anti vectorielle au niveau familial.Bull Soc Pathol Exot. 1992;85(1):26-30. This article on PubMed

20. Languillon J, Mouchet J, Rivola $\mathrm{E}$, RateauJ. Contribution a l'étude de l'épidémiologie du paludisme dans la région forestière de Cameroun Paludometric, espèces plasmodiales, anophelisme, transmission. Med Trop Mars. 1956; 16: 347-378. This article on PubMed

21. Service MW. Community participation in vector-borne disease control. Ann Trop Med Parasitol. 1993 Jun;87(3):223-34. This article on PubMed

22. Maps, Weather, and Airports for Ndu, Cameroon (2011). Available at : Maps, weather, videos, and information about Ndu, Cameroon

23. Launiala A. How much can a KAP survey tell us about people's knowledge, attitudes and practices? Some observations from medical anthropology research on malaria in pregnancy in Malawi. Anthrop Mat. 2009; 11:1-14

24. Ruebush TK, Kern MK, Campbell CC, Oloo AJ. Self-treatment of malaria in a rural area of Western Kenya. Bull World Health Organ. 1995;73(2):229-36. This article on PubMed

25. Faye O, NdirO, Gay O, Bah IB, Dieng T, Dieng Y, Diallo S, DiagneAK. Population practices in the diagnosis of malaria and use of antimalarial drugs in Dakar. Med Trop (Mars). 1995;55(1):47-50. This article on PubMed

26. Zurovac D,Ndhlovu M, Rowe AK, Hamer DH, Thea DM, Snow RW. Treatment of paediatric malaria during a period of drug transition to artemether-lumefantrine in Zambia: cross-sectional study. BMJ. 2005; 331:706-707. This article on PubMed

27. Yeneneh H, Gyorkos TW, Joseph L, Pickering J, Tedla S. Anti-malarial drug utilization by women in Ethiopia: a knowledge-attitudespractice study. Bull World Health Organ. 1993;71(6):763-72. This article on PubMed

28. Kloos H, Etea A,Defega A. Illness and health behaviour in Addis Ababa and rural Central Ethiopia. Soc Sci Med. 1987;25(9):1003-19. This article on PubMed

29. Good B. Medicine, rationality and experience: An anthropological perspective. Cambridge: Cambridge University Press. 1994

30. Glik DC, Ward WB, Gordon A, Haba F. Malaria treatment practices among mothers in Guinea. J Health Soc Behav. 1989 Dec;30(4):42135. This article on PubMed

31. Deming M, Gayibor A, Murphyl K, Jones TS, Karsa T. The home treatment of febrile children with antimalarial drugs in Togo.Bull World Health Organ. 1989;67(6):695-700. This article on PubMed

32. Foster S. Treatment of malaria outside the formal health services. J Trop Med Hyg. 1995; 98: 29-34. This article on PubMed

33. Greenberg AE, Ntumbanzondo M, Ntula N,Mawa L, Howell J, Javachi F. Hospital-based Surveilliance of malaria ' related pediatric morbidity and mortality in Kinshasa, Zaire. Bull World Health Organ. 1989;67(2):189-96. This article on PubMed

34. Raikes A. Women's health in East Africa. Soc Sci Med. 1989;28(5):447-59. This article on PubMed 
Table 1: Demographic characteristics of the study participants $(n=253)$

\begin{tabular}{|c|c|}
\hline Demographic characteristics & No (\%) \\
\hline \multicolumn{2}{|l|}{ Age range(years) } \\
\hline $21-25$ & $24(9.5)$ \\
\hline $26-30$ & $17(6.7)$ \\
\hline $31-35$ & $86(34.0)$ \\
\hline $36-40$ & $21(8.3)$ \\
\hline $41-45$ & $33(13.0)$ \\
\hline $46-50$ & $52(20.6)$ \\
\hline$\geq 50$ & $20(7.9)$ \\
\hline \multicolumn{2}{|l|}{ Sex } \\
\hline Male & $112(44.3)$ \\
\hline Female & $141(55.7)$ \\
\hline \multicolumn{2}{|l|}{ Occupation } \\
\hline Labourers & $99(39.1)$ \\
\hline Farmers & $40(15.8)$ \\
\hline Teachers & $16(5.3)$ \\
\hline Medical personnel & $8(3.2)$ \\
\hline Housewives & $20(7.9)$ \\
\hline Students & $6(2.4)$ \\
\hline Unemployed & $64(25.3)$ \\
\hline \multicolumn{2}{|l|}{ Tribe } \\
\hline Wimbum & $228(90.1)$ \\
\hline Yambah & $09(3.6)$ \\
\hline Fulani & $11(4.3)$ \\
\hline Others & $05(2.0)$ \\
\hline \multicolumn{2}{|l|}{ Place of abode } \\
\hline Hills & $116(46.0)$ \\
\hline Valleys & $137(54.0)$ \\
\hline \multicolumn{2}{|l|}{ Educational status } \\
\hline Primary and less & $155(61.3)$ \\
\hline Secondary and above & $98(38.7)$ \\
\hline \multicolumn{2}{|l|}{ Religion } \\
\hline Christian & $217(85.8)$ \\
\hline Muslim & $11(4.2)$ \\
\hline Others & $25(10.0)$ \\
\hline
\end{tabular}

No: Number, \%: Percentage 
Table 2: Variation of knowledge of reasons of antimalarial drug resistance with gender among the study participants $(n=253)$

\begin{tabular}{|c|c|c|c|}
\hline \multirow[t]{3}{*}{ Reasons for malaria resistance } & \multirow[t]{3}{*}{ No (\%) } & \multicolumn{2}{|c|}{ Gender } \\
\hline & & Male & Female \\
\hline & & No (\%) & No (\%) \\
\hline \multicolumn{4}{|l|}{ Correct Reasons } \\
\hline When fever continues for a long time during treatment & $52(20.6)$ & $15(13.4)$ & $37(26.2)$ \\
\hline When fever is severe during treatment & $15(5.9)$ & $8(7.1)$ & $7(5.0)$ \\
\hline When chloroquine does not stop the fever & $18(7.1)$ & $7(6.3)$ & $11(7.8)$ \\
\hline \multicolumn{4}{|l|}{ Incorrect Reasons } \\
\hline Don't know & $126(49.8)$ & $70(62.5)$ & $56(39.7)$ \\
\hline No response & $42(16.6)$ & $12(10.7)$ & $30(12.3)$ \\
\hline Total & 253(100) & 112(44.3) & 141(55.7) \\
\hline
\end{tabular}

$\mathrm{X}^{2}=4.6, \mathrm{P}$-value $=0.01 ;$ No: Number; \%: Percentage

Table 3: Variation of knowledge of antimalarial drug resistance among different age groups of the study participants ( $n=253)$

\begin{tabular}{|c|c|c|c|}
\hline \multirow[t]{3}{*}{ Age group (Years) } & \multicolumn{2}{|c|}{ Knowledge of malaria resistance } & \multirow{3}{*}{$\begin{array}{c}\text { Total } \\
\text { No }(\%)\end{array}$} \\
\hline & Know & Don't know & \\
\hline & No (\%) & No (\%) & \\
\hline $21-25$ & $14(16.5)$ & $10(6.0)$ & $24(9.5)$ \\
\hline $26-30$ & $6(7.1)$ & $11(6.6)$ & $17(6.7)$ \\
\hline $31-35$ & $23(27.1)$ & $63(37.5)$ & $86(34.0)$ \\
\hline $36-40$ & $8(9.4)$ & $13(7.7)$ & $21(8.3)$ \\
\hline $41-45$ & $12(14.1)$ & $21(12.5)$ & $33(13.0)$ \\
\hline $46-50$ & $18(21.2)$ & $34(20.2)$ & $52(20.6)$ \\
\hline$\geq 50$ & $4(4.7)$ & $16(5.2)$ & $20(7.9)$ \\
\hline Total & $85(33.6)$ & $168(66.4)$ & 253(100) \\
\hline
\end{tabular}

$\mathrm{X}^{2}=10.4, \mathrm{df}=6, \mathrm{P}$-value=0.1; No: Number; \%: Percentage; 
Table 4: Variation of knowledge of antimalarial drug resistance and profession of the study participants $(n=253)$

\begin{tabular}{|c|c|c|c|}
\hline \multirow[t]{2}{*}{ Profession of participants } & \multicolumn{2}{|c|}{ Knowledge of malaria resistance } & \multirow[b]{2}{*}{$\begin{array}{c}\text { Total } \\
\text { No }(\%)\end{array}$} \\
\hline & $\begin{array}{c}\text { Know } \\
\text { No (\%) }\end{array}$ & $\begin{array}{c}\text { Don't know } \\
\text { No }(\%)\end{array}$ & \\
\hline \multicolumn{4}{|l|}{$\begin{array}{l}\text { Professions requiring a } \\
\text { certain level of education }\end{array}$} \\
\hline Medical staff & $8(9.4)$ & $0(0.0)$ & $08(3.2)$ \\
\hline Teaching & $16(18.8)$ & $0(0.0)$ & $16(6.3)$ \\
\hline Students & $4(4.7)$ & $2(1.2)$ & $06(2.4)$ \\
\hline \multicolumn{4}{|c|}{$\begin{array}{l}\text { Professions requiring no level } \\
\text { of education }\end{array}$} \\
\hline Farming & $10(11.8)$ & $30(17.9)$ & $40(15.8)$ \\
\hline Labourers & $14(16.5)$ & $85(50.6)$ & $99(39.1)$ \\
\hline Housewives & $14(16.5)$ & $6(3.6)$ & $20(7.9)$ \\
\hline Unemployed & $19(22.4)$ & $45(26.8)$ & $64(25.3)$ \\
\hline Total & $85(33.6)$ & $168(66.4)$ & 253(100) \\
\hline
\end{tabular}

$\mathrm{X}^{2}=80.8, \mathrm{df}=6, \mathrm{p}=0.0 ;$ No: Number; \%: Percentage 


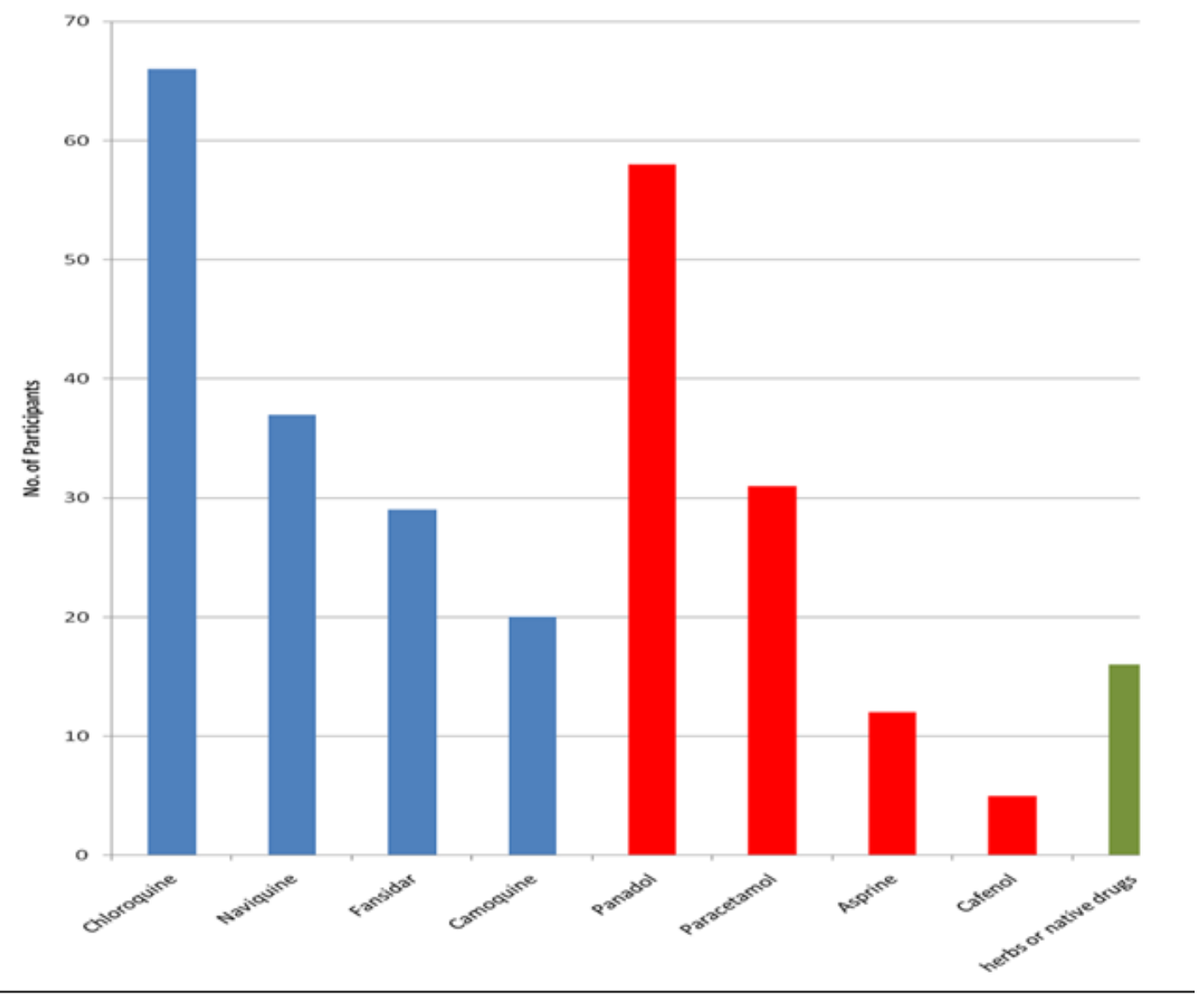

Figure 1

Drugs used for the practice of self-treatment of malaria as stated by the study participants $(n=253)$

Blue: Anti-malarials, Red: Analgesics, Green: Traditional medicine .

NB: Frequency of responses is greater than 253 because of multiple responses 


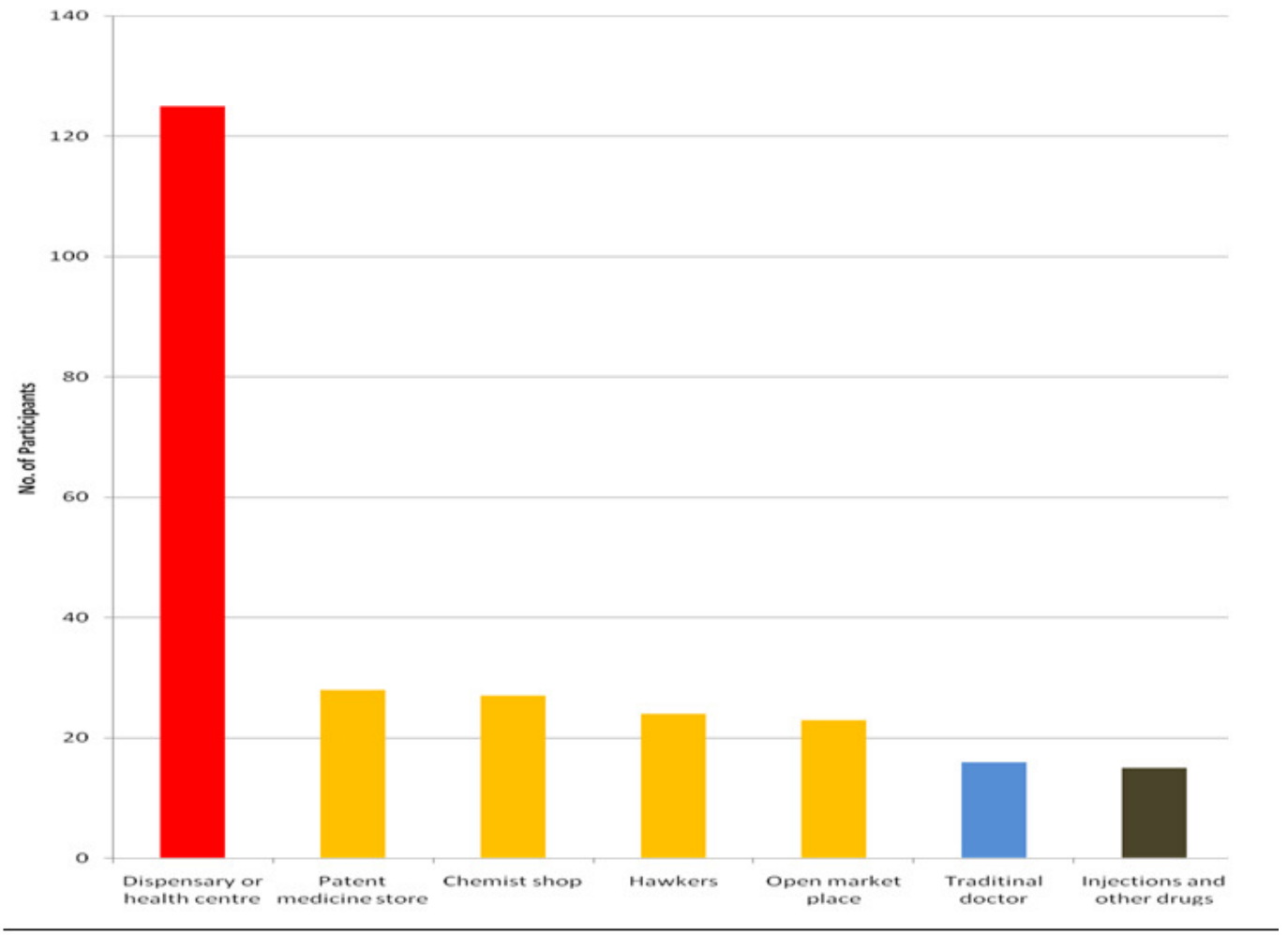

Figure 2

Sources of getting anti-malarials as stated by the study participants $(n=253)$

NB: Frequency of responses is greater than 253 because of multiple responses

Red: Medication from authorized sources, Yellow: Medication from unauthorized sources, Blue: Traditional medicine sources, Black: Injections 